\begin{tabular}{|c|c|}
\hline Title & $\begin{array}{l}\text { Ecological function losses caused by monotonous land use induce crop raiding by wildlife on the island of } Y \text { akushima, } \\
\text { southern Japan }\end{array}$ \\
\hline Author(s) & A getsuma, Naoki \\
\hline Citation & $\begin{array}{l}\text { Ecological Research, 22(3), 390-402 } \\
\text { https://doi.org/10.1007/s11284-007-0358-z }\end{array}$ \\
\hline Issue Date & 2007 \\
\hline Doc URL & http:/hdl.handle.net/2115/47080 \\
\hline Rights & The original publication is available at www.springerlink.com \\
\hline Type & article (author version) \\
\hline Note & $\begin{array}{l}\text { From the issue entitled "Special Feature on Sustainability and Biodiversity of Forest Ecosy stems: An Interdisciplinary } \\
\text { A pproach" }\end{array}$ \\
\hline Additional Information & There are other files related to this item in HUSCAP. Check the above URL. \\
\hline File Information & es22_e.pdf (本文) \\
\hline
\end{tabular}

Instructions for use 


\title{
Ecological function losses caused by monotonous land use induce crop raiding by wildlife on the island of Yakushima, southern Japan. $<$ HUSCAP 利用者のための本文和訳つき $>$
}

\author{
Naoki Agetsuma \\ Tomakomai Experimental Forest \\ Field Science Center for Northern Biosphere, Hokkaido University \\ Takaoka, Tomakomai 053-0035 Japan. agetsuma@ fsc.hokudai.ac.jp
}

\begin{abstract}
Mass production is a logical outcome of price competition in a capitalist economy. It has resulted in the need for large-scale logging and planting of commercial crops. However, such monotonous land use, or monoculture, has damaged various ecological functions of forests and eroded the beneficial public service provided by forests. In Japan, the most widespread monotonous land use is associated with coniferous plantations, the expansion of which was encouraged by Forest Agency policies from 1958 that were aimed at increasing wood production. By 1986, half of all forested lands had been transformed into single-species conifer plantations. These policies may damage the ecological functions of forests: to provide stable habitats for forest wildlife. In particular, food supplies for wildlife have fluctuated greatly after several decades of logging. Some species have therefore changed their ecology and begun to explore novel environments proactively in order to adapt to such extreme fluctuations. Such species have started to use farmlands that neighbor the plantations. In this sense, crop raiding by wildlife can be regarded as a negative result of monotonous land use due to the loss of ecological functions. Therefore, habitat management to rehabilitate ecological functions and to reorganize the landscape will be required in order to resolve the problem of crop raiding by wildlife. This study examines crop raiding by Japanese deer (Cervus nippon) and monkeys (Macaca fuscata) on the island of Yakushima, which typifies crop-raiding situations in Japan.
\end{abstract}

\section{Keywords}

Crop raiding - Functional response - Land use management - Plantation - Wildlife ecology

\section{Monotonous forest and deterioration of ecological functions}

Mass production is a logical outcome of price competition in a capitalist economy. It has necessitated intensive and monotonous land use for primary industries, especially large-scale logging, and the planting of commercial crops. Typical examples are the monocultures of coffee, 
palm, gum and sugarcane that are cultivated widely throughout tropical and subtropical regions (e.g., Nagata et al. 1994; Hartemink 2005). However, such monotonous land use, or monoculture, has damaged ecological functions and services provided by forest ecosystems, including those which benefit the public (e.g., McNeely et al. 1990; Lugo 1997).

In Japan, monotonous land use has developed mainly as the large-scale logging of natural forests and their replacement with coniferous trees, in accordance with the policies of the Forest Agency from 1958, which were aimed at increasing wood production (e.g., Japan Federation of Bar Associations 1991). Originally, Japanese forests consisted mainly of numerous broad-leaved species (i.e., summer green and evergreen broad-leaved forests: e.g., Miyawaki and Okuda 1978). However by 1986, half of all forested land had been logged and transformed into conifer plantations consisting of mainly single species, such as Japanese cedar (Cryptomeria japonica) and cypress (Chamaecyparis obtusa). Nonetheless, the financial situation of the Forest Agency administrating the National Forest worsened after 1973 for various reasons, including the start of mass importation of wood (e.g., Japan Federation of Bar Associations 1991). The situation for private forest owners was similar or worse. The cumulative debt of the Forest Agency in 1998 amounted to nearly $¥ 4,000$ billion ( $c$. $\$ 30$ billion). These policies have brought not only financial burdens to Japan, but they have also caused various environmental problems. In general, monotonous plantations exert various negative influences on the ecological functions of forest ecosystems. Conifer plantations in Japan decrease species diversity and disturb the species compositions of plant (e.g., Nagaike 2002) and animal communities (e.g., Saitoh and Nakatsu 1997; Maeto et al. 2002). Various material flows are influenced by such activities (e.g., Nakane 1995); mudslides occur frequently in logging and plantation areas (e.g., Inagaki 1999). Moreover, increasing numbers of Japanese people suffer allergies from cedar pollen (e.g., Inoue et al. 1986). These can be regarded as negative impacts of monotonous plantations through the deterioration of ecological functions and services.

Logging natural forests and transforming them into monotonous plantations profoundly disturbs the habitats of many mammals. For example, food supplies for herbivores tend to fluctuate greatly for around 20 years after logging and planting in Japan (e.g., Koizumi 1988; Sone et al. 1999; Hanya et al. 2005). Logging initially destroys food production, but it soon increases after improved exposure of the field layer to light. It then decreases rapidly to minimum levels, concomitant with tree growth (Fig. 1). These great fluctuations occur for two decades after logging. After this, productivity gradually recovers in a process that takes several decades or longer, even if vegetation regenerates naturally (Fig. 1a). Thus, forest mammals have been exposed to extreme fluctuations in food availability over long periods. Some species, such as deer (Cervus nippon), monkey (Macaca fuscata) and serow (Capricornis crispus), have begun to adapt various aspects of their ecology (diet selection, range use, daily rhythm, dispersion, reproduction, life history, social relation, etc.) and to proactively explore novel environments (farmlands neighboring the plantations and logging areas). By adaptating to these new habitats, these mammals have started to damage agricultural crops (Agetsuma 1999b, 2006). In this sense, crop raiding by mammals can also be regarded as a negative impact of monotonous plantations. 


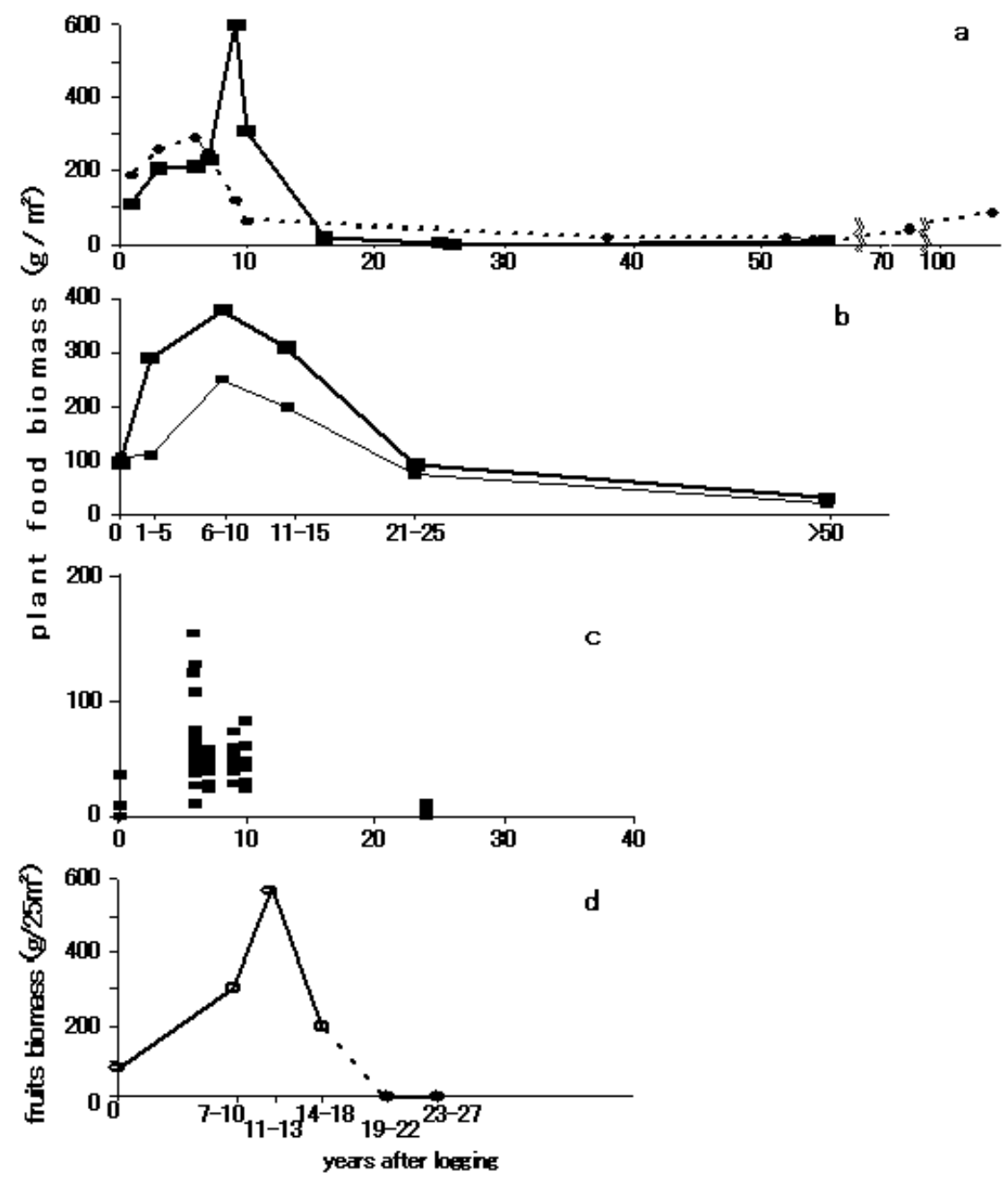

Fig. 1a-d Food plant biomass (dry weight $/ \mathrm{m}^{2}$ ) after clear-cut logging of broad-leaved forests. a, Food plant biomass under cedar plantations (solid line) and that under secondary broad-leaved forests for Japanese sika deer (broken line; modified from Takatsuki 1992). b, Food plant biomass under conifer plantations in November (solid line) and in August for Japanese serow (thin line; drawn from Sone et al. 1999). c, Food plant biomass under cedar plantations for Japanese serow (squares: modified from Ochiai 1996). d, Biomass of fruit, which is an important food for Japanese monkey, in primary and secondary broad-leaved forests (open circles), and cedar plantations (solid circles; modified from Hanya et al. 2005).

A typical case is that of Yakushima Island in Japan, which was designated as a World Heritage site in 1993. As in most parts of Japan, large-scale logging and transformation to conifer plantations has engendered various environmental problems on this island. The diversity of woody plants and buried seeds has decreased in plantation forests (Aiba, unpublished data). Some insect taxa have also decreased in secondary forests and decreased greatly in plantations (Yumoto, unpublished data), while the diversity of foraging bat species has also decreased in plantations (Hill, unpublished data). Mudslides have occurred frequently in and around logging areas and young plantations (Japan Institute of Land and Environmental Studies 1981). These facts suggest that deterioration of ecological function due to the transformation to monotonous forest has occurred in 
Yakushima. Endemic subspecies of Japanese deer (C. n. yakushimae) and monkeys (M. f. yakui) inhabit the whole of this island. They have experienced great habitat disturbance as a result of the transformations. After extensive forest transformations (in the 1960s to 1970s), these species began to intensively damage crops (in the 1980s to 1990s). This paper presents a review of the processes and factors associated with agricultural crop raiding by these mammals in relation to forest development in Yakushima, referring to cases from other locations in Japan. Then, the importance of land use management is examined to determine a possible route to recovering the damaged ecological functions, in order to prevent crop raiding as well as to conserve wildlife.

\section{Forest development}

Yakushima is a round mountainous island $(\mathrm{ca} .500 \mathrm{~km} 2)$ located in southern Japan $\left(30^{\circ} \mathrm{N}\right.$, $130^{\circ} \mathrm{E}$ ). About 14,000 residents populate its two townships. Most villages are located less than 100 $\mathrm{m}$ above sea level (a.s.1.); most other areas are forested (Fig. 2). About $80 \%$ of the forested area is National Forest property. From 0 to $800 \mathrm{~m}$ a.s.l., natural forests consist mainly of evergreen broad-leaved trees. Then, from 800 to $1,800 \mathrm{~m}$, forests consist of both broad-leaved and coniferous trees. There are many natural Japanese cedars, especially at over 1,200 m a.s.1. (Tagawa 1994). Cedars more than 1,000 years old are called "Yaku Sugi," and they produce very valuable timber (Kamiyaku Town 1984). Annual precipitation at lower altitudes is 2,500-5,000 mm, and that at higher altitudes is up to 7,000 mm, and occasionally 10,000 mm (Kagoshima Prefecture 1992). On the coasts, the annual mean temperature is around $20^{\circ} \mathrm{C}$, which corresponds to the margin between subtropical and warm temperate zones (Tagawa 1994). On the other hand, above 1,000 $\mathrm{m}$ a.s.1., the climate is much cooler, with snow cover in winter.

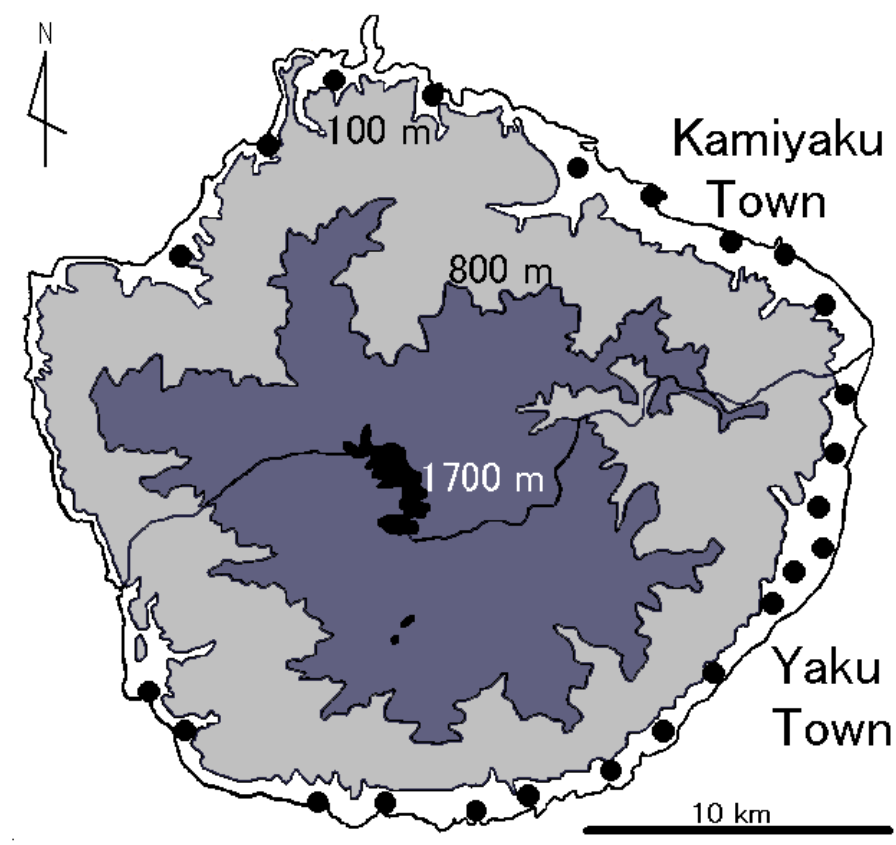

Fig. 2 The island of Yakushima. Villages are represented as dots. Contours show 100, 800 and 1,700 m a.s.l. A line shows the boundary between the two towns. 

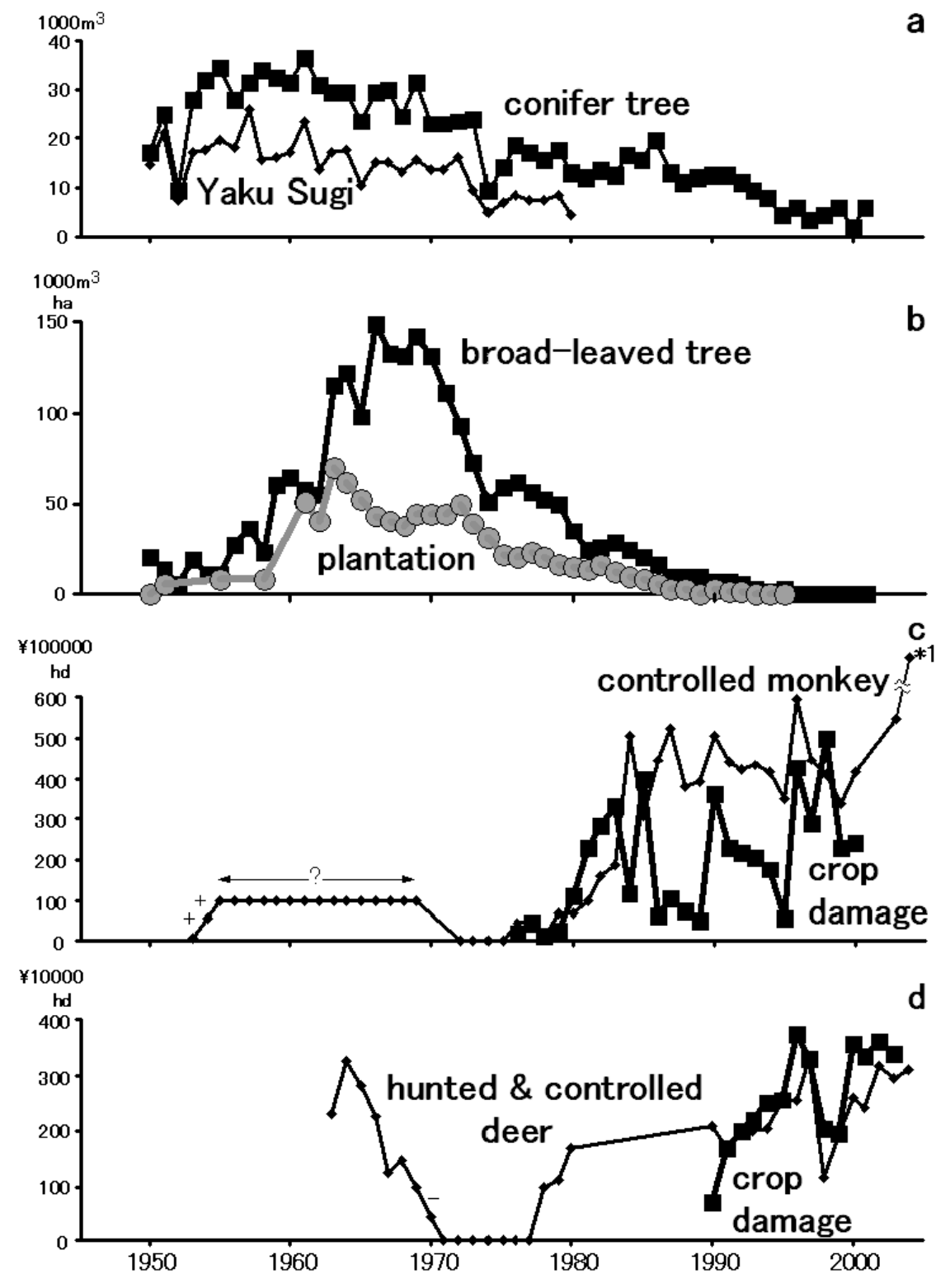

Fig. 3a-d Annual logging volumes, conifer planting area, agricultural crop damage by wildlife, and number of hunted animals. "+” indicates possibly underestimated values; "-"” indicates possibly overestimated values; and "?" indicates approximate values in the figure. a, Logging volume of conifer trees (solid line; Suwa, personal data) and those of cedar (thin line; Miura 1984; Fujimura 1971). These trees were logged at the higher altitudes of Yakushima. b, Logging volume of broad-leaved trees (solid line; Suwa, personal data) and conifer plantation area (gray line; data from Kagoshima Pref.; data from Forest Agency). Broad-leaved trees were logged at both higher and middle altitudes. However, after 1963, they were mainly logged at middle altitudes. c, Amount of crop damage ( $¥ ¥ 100,000, c a$. $\$ 800$ ) by monkeys (solid line) and number of monkeys killed (thin line; Agetsuma 1998; Azuma 1984; Hirose 1984; data from Kagoshima Pref.). The value at*1 is 833 individuals. Monkeys were captured for experimental use in the 1950s and 1960s. After 1972, all captures were conducted as pest control measures. $d$, Amount of crop damaged ( $x ¥ 10,000)$ by deer (solid line) and the number of deer hunted and controlled (thin line; Kagoshimaken Shizen Aigo Kyokai 1981; Sueyoshi 1992; data from Kagoshima Pref.). During 1971-1977, deer hunting was prohibited. Since 1999, deer control has been concentrated around farms. 
Intensive logging in Yakushima began in the upper area for Yaku-Sugi. The logging of conifer trees increased around 1950 and decreased in the 1960s because of tree depletion (Fig. 3a). During 1955-1973, because the Japanese economy grew rapidly (average GNP growth rate was 9.1\% per year according to data from the Cabinet Office of the Government of Japan), there was increased demand for wood and pulp production (Japan Federation of Bar Associations 1991). The logging area was then shifted to broad-leaved forests in the middle altitudes in Yakushima. The volumes of broad-leaved trees logged increased greatly from 1963, but decreased after 1973 (Fig. 3b), when the market price of wood dropped (Japan Federation of Bar Associations 1991), the number of trees that could be logged decreased, and the social trend of nature conservation became more popular (Kamiyaku Town 1984). After logging broad-leaved trees, Japanese cedar were widely planted in areas that were not the original habitat for the species (Fig. 3b).

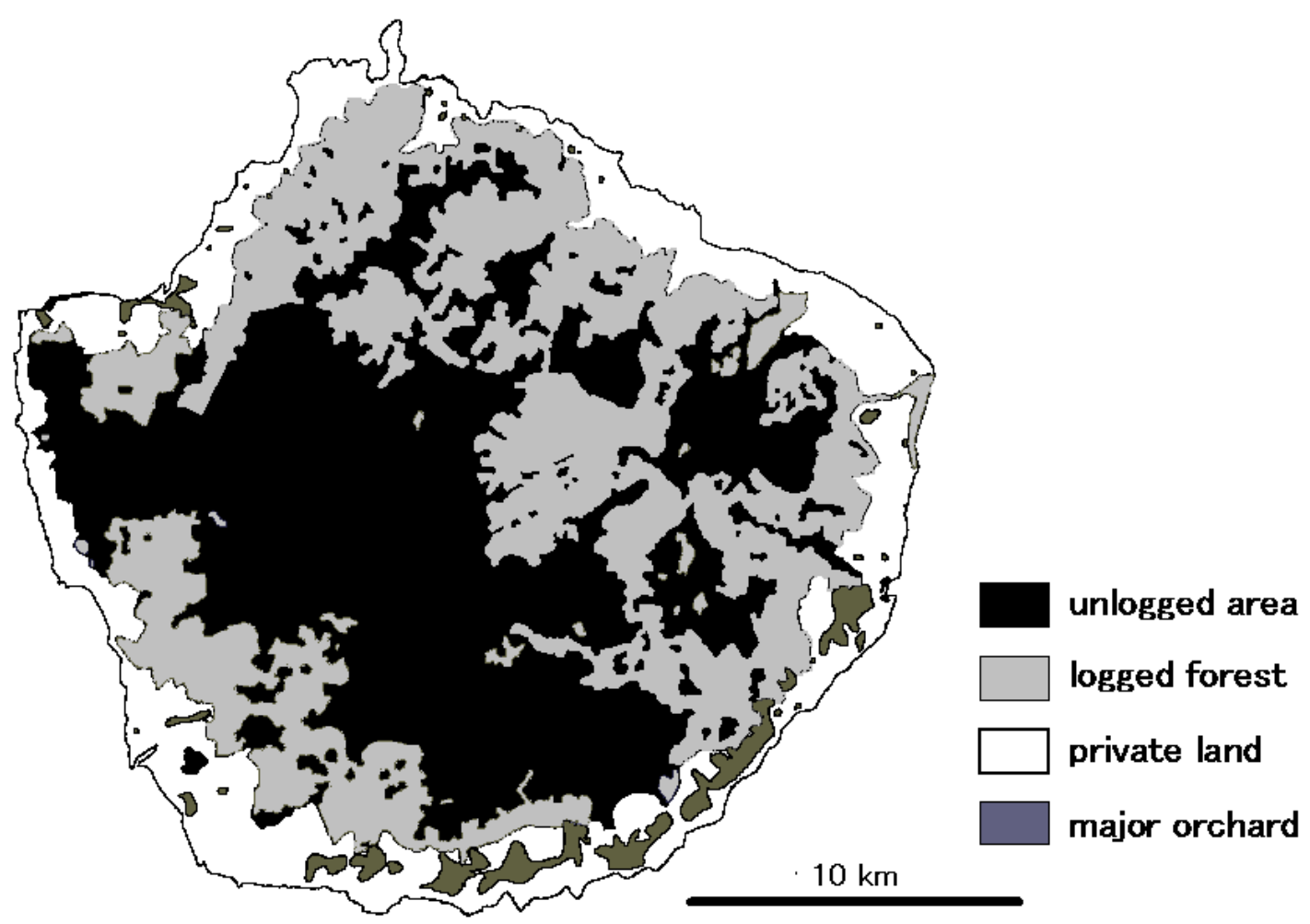

Fig. 4 Areas logged by 1983 and the main orchard in Yakushima (modified Agetsuma 1996). Very small unlogged forests among large logged forests were classified as logged areas. Solid areas indicate unlogged forests. Lightly shaded areas indicate logged areas. Open areas around coasts indicate private lands; dark-shaded areas indicate major orchards.

Figure 4 shows logged areas in the National Forests of the island up to 1983. As the logging continued after 1983 (Fig. 3a,b), the actual total area logged must be much greater than shown. Most of the logging took place within a period of 20-30 years, and a quarter of all forested areas were transformed into monotonous conifer plantations (Kagoshima Prefecture 1992). The plantations were particularly dense at middle-to-low altitudes on this island. 


\section{Land use changes in lower areas}

Social and economic structures in regional societies in Japan, as well as those at a national level, are closely related to local land uses (Agetsuma 1999a). Below $300 \mathrm{~m}$ a.s.l. in Yakushima, the residents deforested the land and used it intensively for traditional purposes such as swidden cultivation, fuel wood, and charcoal (Sprague, unpublished data). Green fertilizer and litter for compost might also have been collected from the forest. As a result, "rough land," i.e., treeless land, spread extensively by the 1920s (Sprague, unpublished data). As both monkeys (Agetsuma 1995a, 1995b, 2001; Hanya et al. 2004) and deer (Agetsuma and Agetsuma-Yanagihara 2006) in natural forests in Yakushima depend largely on the production of tall trees, the treeless land might not be so valuable to them, although the deer could feed on herbaceous plants (Takatsuki 1990) and monkeys can feed on the fruits of some shrubs (Hanya et al. 2005). Higher human activity in farmlands would also have limited the utility of such places for animals. However, a fuel and fertilizer revolution then occurred. In addition, because of the shift in the industrial structure of this island, the number of farmers and the area of farmed land decreased greatly between 1950 and 1975 (Fig. 5a). In addition, some areas of treeless land and farm areas were rapidly converted into orange orchards around 1970 due to the promotional efforts of local governments (Fig. 5b; Agetsuma 1998). Some broad-leaved forests were also transformed into orange orchards at that time. Most treeless lands were abandoned and subsequently reverted to broad-leaved forests (Sprague, unpublished data), thereby providing many resources for animals after the 1970s. Consequently, the total area of treeless land decreased in the lower areas, while the areas of broad-leaved forests and orange orchards simultaneously increased. Production of oranges increased greatly after 1980 (Fig. 5b), but this industry has increasingly been damaged by wildlife.

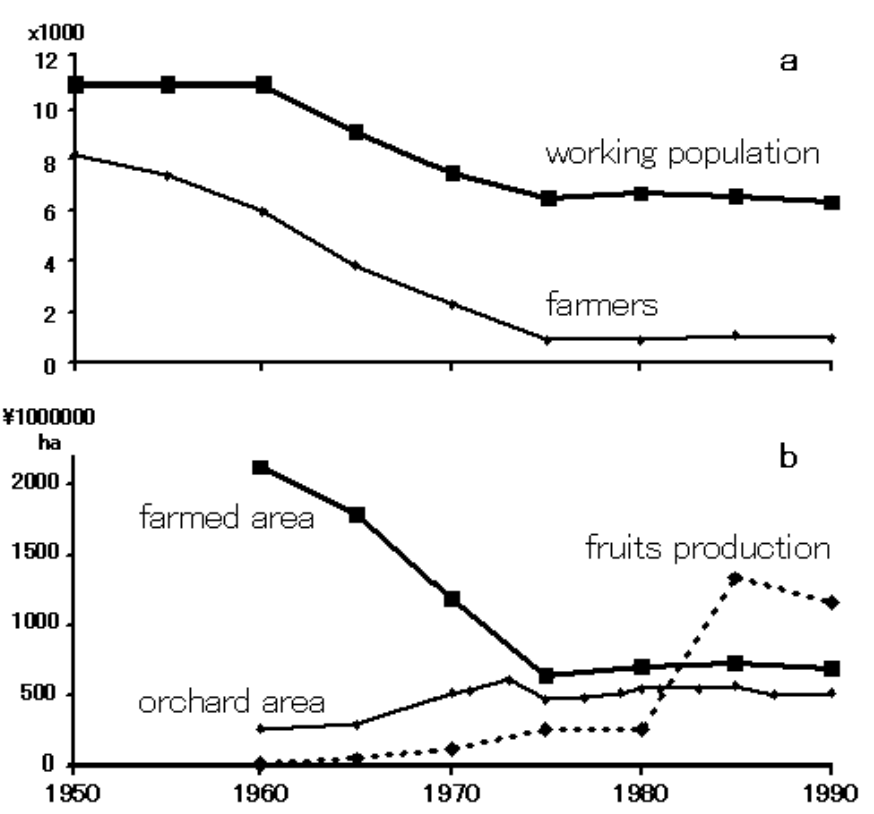

Fig. 5a-b Working population, farmland area and fruit production $(\times ¥ 1000,000, c a . \$ 8,000)$ in Yakushima. a, Total working population (solid line) and number of people engaged in agriculture (thin line; Kagoshima Prefecture 1992). b, Farm areas of the five main crop items (solid line); that of orchards (thin line); and fruit production (broken line; Agetsuma 1998; Kagoshima Prefecture 1992). 


\section{Outbreaks of crop raiding and pest control}

The population of raiding monkeys was estimated to be roughly 1,600-3,100 in 1991-1992 (see Table 1 of Yoshihiro et al. 1998, excluding Area 7 where there was no farmland), but there are estimated to be many other monkeys that bear no influence on crops in Yakushima (e.g., Hanya et al. 2004). The monkeys mainly damage oranges and other fruits, as well as sweet potatoes (data from Kamiyaku Town). Crop raiding by monkeys began before 1950 in Yakushima (Itani 1994). However, the amount of damage increased greatly after 1980, which was about 15 years after the peak of broad-leaved forest logging (Fig. 3b,c). Therefore, before the monkeys started to damage crops intensively, they had experienced great disturbances to their habitat through logging and planting.

Pest control of monkeys have been conducted from at least the 1910s (e.g., Kagoshima Dairinkusho 1916). After 1978, local governments greatly increased the number of monkeys controlled. However, from 1978 to 1983, even though more monkeys were controlled, there was still increased damage to crops (Fig. 3c). Thereafter, high levels of damage have continued to occur, even though 300-600 monkeys have been killed every year since 1984. It could be argued that an increase in the monkey population has been averted by controlling 300-600 monkeys since 1984 . However, the number of monkeys removed has not been determined by scientific means, nor in response to the intensity of damage. Rather it has been mainly influenced by voluntary efforts of local hunters and the availability of subsidies from the local government. Therefore, it would be a lucky coincidence if the number of monkeys that were removed happened to be the number required to stop population growth. It seems much more likely that the rate of population increase varies to match the number of monkeys removed, thereby maintaining a fairly constant population size. The annual amount of damage by monkeys has varied greatly. Some of this variation might be attributable to interannual differences in the production of wild fruits (Noma, unpublished data), which are very important foods for monkeys during any season in the forests (e.g., Agetsuma 1995b, 2001; Hanya 2004).

Severe raiding of agricultural crops by deer in Yakushima has occurred since at least the eighteenth century (Kamiyaku Town 1984). In addition, Matsuda (1997) documented deer raiding fields in the 1950s. However, crop raiding by deer greatly increased around 1990 (Fig. 3d). This period was around 25 years after the logging peak of broad-leaved forests (Fig. 3b). The crops damaged were mainly orange trees (by bark stripping; data from the Kagoshima Prefecture), sweet potatoes and rice (Sueyoshi 1992). On the other hand, damage to planted conifer trees has decreased from the 1990s onwards (data from the Kagoshima Prefecture). This may be explained simply by the decline in newly planted areas after the 1970s (Fig. 3b) and the consequent decrease in the number of small planted saplings that are vulnerable to deer.

Deer hunting was traditionally conducted in Yakushima. By around 1950, more than 1,000 deer could be hunted per year (Kamiyaku Town 1984). However, the number of deer hunted decreased rapidly during 1964-1970 (Fig. 3d). Ultimately, deer hunting was banned from 1971, but was brought back for pest control from 1978. However, the damage caused by deer to crops and forestry did not seem to be substantial during this period (Tagawa 1987). Deer control was 
conducted over the whole island using very similar methods to those used when hunting before the ban, including at middle and even upper altitudes. Therefore, deer that took no interest in crops were also controlled. However, from 1999, deer control has been limited to areas around farmlands so that actual raiding deer are targeted. Since the number of deer controlled per year has stayed at around 200-300 since 1980 (Fig. 3d), raiding deer are now being controlled more intensively than before 1999. Nevertheless, the amount of crop damage has not decreased. As with the monkeys, raiding deer might also adapt to maintain their population size after depletion by intensive pest control.

Two common tendencies are recognizable in the crop raiding by both mammals in these empirical data. One is the timing of the rapid increase in crop raiding, which occurs after a delay of around 20 years from the logging peak of broad-leaved forests (Fig. 3b-d). Another is the ineffectiveness of pest control at reducing crop damage. It has often been mentioned that pest control is ineffective at protecting crops from monkeys (e.g., Ministry of the Environment 2000; Hakusan Nature Conservation Center 1995). In addition, deer control appears to have had no beneficial effects in Yakushima to date.

\section{Impacts of forest development on the ecology of mammals}

The impacts of the transformation of natural forests into monotonous conifer plantations on the ecology of wildlife take a variety of forms, altering diet, habitat use and various behaviors (Gill et al. 1996). Some ecological functions are degraded by the transformation. The population density can be used as an easily detectable index to evaluate those impacts.

Monkey group density tends to have been degraded by the spread of plantations in Yakushima (Hill et al. 1994; Hanya et al. 2005). Food production of naturally regenerated young forests ( $<20$ years old approx.) for monkeys is higher than that of primary forests. However, that of plantation forests (>20 years old) is very low in Yakushima (Hanya et al. 2005). Monkey group density corresponds closely to the food production of forests in Yakushima (Hanya et al. 2004; 2005). Various negative impacts of conifer plantations on Japanese monkeys have also been reported in other places. Monkey groups tend to avoid plantations within their ranges (e.g., Shirai 1993; Hakusan Nature Conservation Center 1995). Therefore, they must expand their ranging area after the establishment of conifer plantation nearby in order to compensate for that area's lower productivity (Furuichi et al. 1982). The topography of areas where cedar plantations have been established has made matters worse. Japanese cedar is typically planted in valleys and lower side slopes (e.g., Yamabayashi 1962), where food plant species diversity for monkey is high in Yakushima (Agetsuma and Noma 1995). Monkeys have therefore lost these diversified food resources, which they depend upon in spring when food conditions are poor in plantation areas.

Deer greatly depend on leaves and fruits of various woody species in various places at altitudes below $1500 \mathrm{~m}$ a.s.l. in Yakushima, although in some places they feed extensively on graminoides (Takatsuki 1990). In natural forest they are especially dependent upon fallen broad leaves (Agetsuma and Agetsuma-Yanagihara 2006) which arise mainly from tall trees in the canopy. 
However, a few tall broad-leaved trees might be able to regenerate in conifer plantations (e.g., Hanya et al. 2005). Therefore, the increase in food supply several years after logging (Fig. 1) might not be remarkable for monkey and deer in Yakushima, although they may be able to shift their diet to herbaceous plants in the logged areas.

Ohsawa et al. (1995) and Agetsuma et al. (unpublished data) surveyed deer density at four sites with different plantation occupancies in 1994 and 2004. In addition, Agetsuma et al. (2003) estimated the density in natural forests almost free of plantations in 2001. These studies showed that deer densities in heavily planted sites were much lower than those of relatively undisturbed sites (Fig. 6). This indicates that intensive plantations decrease deer density. The impacts cannot be cancelled out, even several decades after planting. Deer hunting and control statistics suggest that the deer population declined soon after intensive logging. Numbers of hunted deer decreased greatly in the 1960s (Fig. 3d). This decrease may indicate a decline in the deer population, but some local people thought that the decrease was caused by a decrease in hunting activity for social and economic reasons (Makise, personal communication). Kagoshimaken Shizen Aigo Kyokai (1981) also suspected that there was a notable decrease in the deer population in the late 1960s. On the other hand, the literature suggests that deer were commonly seen in forests around villages in 1925-1940 (Kamiyaku Town 1984; Miyamoto 1974). Therefore, it is reasonable to assume that deer populations fell precipitously in the 1960s and 1970s. Deer populations seemed to have recovered by the 1990s, as they began to be seen around villages once more (Fig. 3d).

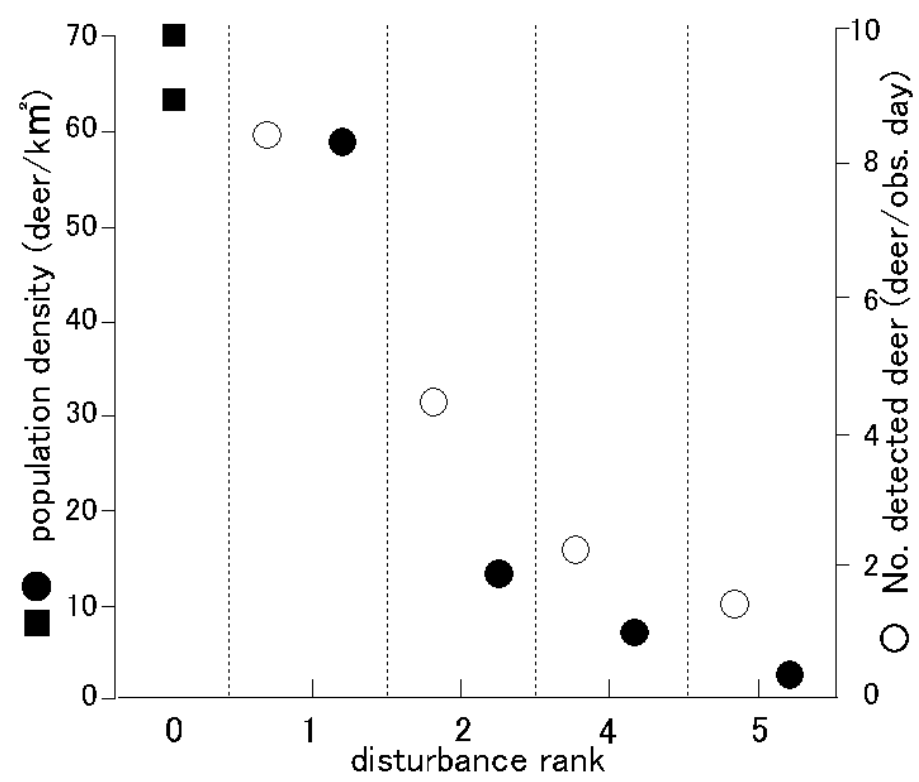

Fig. 6 Relative deer population density at six sites in Yakushima. Solid squares indicate estimated population densities in two lowland natural forests (50-200 m a.s.l.) almost free of plantations in August 2001 (Agetsuma et al. 2003). Solid circles indicate the estimated densities in the autumn of 2004 (Agetsuma et al., unpublished data) and open circles indicate the number of detected deer per observation day in the autumn of 1994 (Ohsawa et al. 1995) at four sites including plantations at middle altitudes (300-700 m a.s.l.). Sites with higher disturbance ranks have as more areas of younger plantations. Disturbance ranks $1-5$ come from Hill et al. (1994). 
A similar decrease in the deer population caused by food depletion due to the establishment of conifer plantations has also been reported in other places (Gill et al. 1996). Roe deer (Capreolus capreolus) increased gradually over the 15 years following conifer planting, but decreased rapidly during the next few years; they then recovered very slowly (Fig. 7). This population dynamic corresponds to a great change in food availability after planting (Gill et al. 1996). A similar tendency is apparent in Japanese serow. Food availability decreased greatly 15 years after the establishment of conifer plantations (Fig. 1b). Changes in serow density corresponded to differences in food availability (Sone et al. 1999). However, these numerical responses to food availability show some time lags (Gill et al. 1996).

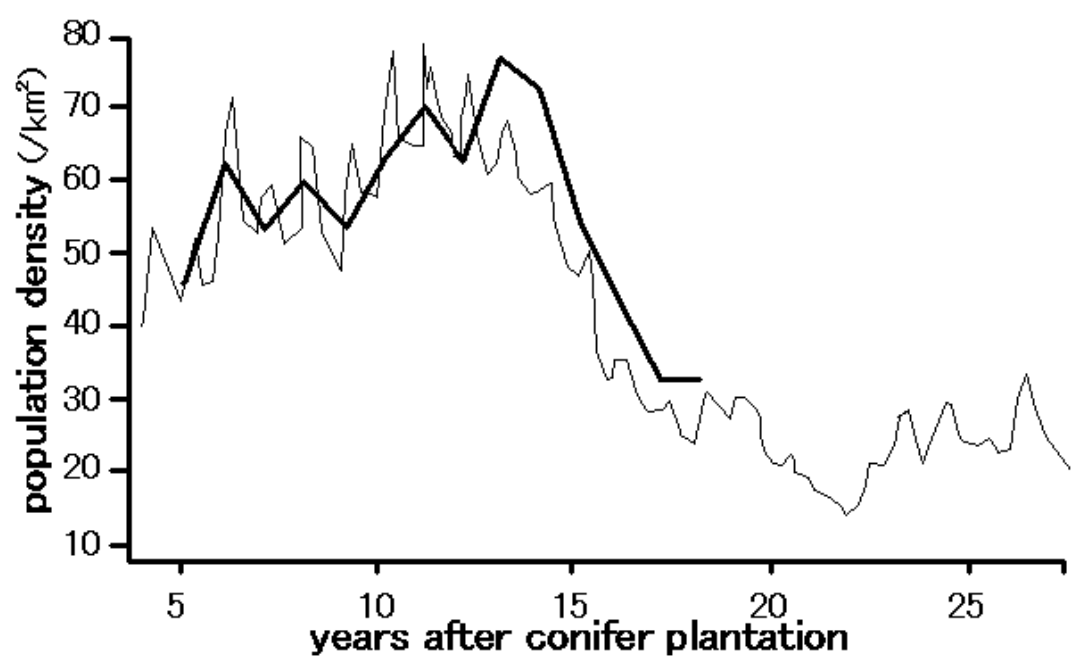

Fig. 7 Population change in roe deer (Capreolus capreolus) after the establishment of conifer plantations (rewritten from Gill et al. 1996). The solid line indicates the density estimated by the hypergeometric maximum likelihood method, and the thin line indicates the density based on the minimum number of known deer. Years after plantation are approximate values. Population density rapidly decreases around 15 years after intensive conifer plantation.

The recovery in the deer density might occur earlier at higher altitudes in Yakushima. Asahi et al. (1984) suspected that the deer density was higher at around 1,000 $\mathrm{m}$ a.s.l. than at lower altitudes after reviewing brief surveys of deer traces conducted in 1981. Intensive logging at higher altitudes began earlier than at middle altitudes (Kamiyaku Town 1984; Fig. 3a,b). In addition, at higher altitudes, much unlogged forest remains and conifer plantations are less widespread (Fig. 4). Therefore, food production might recover earlier in higher areas.

It is probable that populations of monkeys and deer decreased because of the lowered productivity caused by logging and planting. Subsequently, they gradually recovered as production recovered, mainly in naturally regenerating forest stands, from the 1980s. However, they might not recover to their original levels because the production from conifer plantations may still be low in the 2000s and, in fact, their population densities in plantation areas have also been much lower than in undisturbed forests (e.g., Hanya et al. 2005; Fig. 6). 


\section{Possible factors contributing to crop raiding}

Several factors that may contribute to crop raiding and impacts on natural vegetation by wildlife have been suggested in Japan: extinction of natural predators; a decrease in the numbers of wild dogs; decreased snowfall; the expansion of the grasslands; and a decrease in the numbers of hunters (e.g., Matsuda et al. 1999; Miura 1999; Tsuji 1999; Agriculture, Forestry and Fisheries Research Council et al. 2003; Hakusan Nature Conservation Center 1995). These factors have induced population eruptions of pest species. These provide the basis for adopting pest control as measure of this problem. Here, I examine the validity of these factors and their applicability to the case of Yakushima.

\section{- Extinction of wolves and decrease in numbers of wild dogs}

The Japanese wolf (Canis lupus), a natural predator of herbivores, became extinct in 1905 in Japan. Generally in Japan, it is presumed that wolves regulated the number of deer and monkeys to "adequate" densities through predation. Consequently, the wolves must have served to limit the impact of these herbivores on crops and natural vegetation. Without their influence, herbivore populations would have erupted and completely destroyed vegetation (e.g., Stockton 2005; Peterson 1999). However, the effects of wolves on herbivore populations and their impact are not simple. Skogland (1991) reviewed the effects of predators on large herbivore populations using data from long-term studies. That study concluded that predators rarely regulate herbivore populations. Wolves may decrease deer when deer populations are small or decreasing, but they cannot limit large or increasing populations (e.g., Skogland 1991; Messier 1991). In fact, on Hokkaido Island (ca. 78,000 km2) of Japan, more than 100,000 deer were hunted per year around 1870 when wolves still inhabited the island (Kaji 1995): therefore, the deer population must have been several times greater than 100,000, which would be far above the "eruption level" set by Hokkaido Prefecture (2002).

Some studies have reported that reintroduced wolves have decreased the feeding pressure from deer on natural vegetation (e.g., Ripple and Beschta 2004). However, it has also been pointed out that wolves may force deer to modify their range usage (Dussault et al. 2005), and consequently they relieve the intensity of the deer feeding pressure on vegetation in a particular location. In this sense, behavioral changes (i.e., functional response) of deer induced by wolves would be more important than the decrease in the numbers of deer through predation (i.e., numerical response). Moreover, some studies have shown that deer populations are regulated naturally without wolves and hunting, and that they do not unnaturally influence vegetation and nutritional cycles of soils very much, or even facilitate them (e.g., Singer et al. 1998; Boyce 1998).

Another large herbivore inhabiting Japan, the Japanese serow, has also lost its natural predator. In addition, in most places, the government passed laws prohibited serow hunting and control in 1934. Therefore, serow populations should have erupted since then without predation and hunting pressure. The population of this species did indeed increase until the 1990s. However, since then its population density has decreased in various places (e.g., Nawa and Takayanagi 2001; Koganezawa 1999). There has been speculation that the decrease in the serow population is caused 
by severe competition with the increasing numbers of deer (e.g., Koganezawa 1999), but this seems unlikely, as decreasing tendencies are also apparent in areas without deer (e.g., Wildlife Workshop 2003; Miyazawa, unpublished data).

No large or middle-sized carnivores inhabited Yakushima originally (Environment Agency 1984). However, deer and monkeys have sustained their populations in forests which have a great diversity of plant species, including many endemic species (Tagawa 1994). Therefore, it is probable that some natural regulating mechanism functioned in Yakushima to sustain the forest ecosystem. For these reasons, wolf extinction does not seem to be a self-evident cause of the population eruptions of pest species in Japan. Moreover, the smaller body sizes of deer and monkeys in Yakushima are somewhat suggestive. Both deer and monkeys in Yakushima have smaller body sizes than other subspecies in Japan (Izawa et al. 1996). This feature may evolve under food limitation without predation (Kay 1998).

It has been anecdotally pointed out that a decrease in the number of wild dogs may have relaxed the limit on the deer population. However, if wild dogs perform similar functions to those of wolves, they are equally unlikely to regulate the deer population. The number of wild dogs seemed to increase from the late 1990s in the natural forest of Yakushima as the deer population recovered (Agetsuma, personal observation). In this sense, the wild dog population may be supported by the deer population, and their population dynamics might simply track those of deer.

\section{- Decreased snowfall due to global warming}

Another factor might be a decrease in snowfall, attributable to global warming. Snowfall can be a limiting factor on herbivore populations (Skogland 1991). Heavy snows can result in a considerable decrease in population size. If snowfall decreases as a result of global warming, herbivore populations may increase sharply. However, we should note that global warming may not result in increases in the mean annual temperature; it may also increase the frequency of extreme weather (e.g., Sanchez et al. 2004), which might cause very severe winters. For example, many observatories in east Hokkaido have measured record heaviest snow depths since 2000 (data from the Japan Meteorological Agency). Especially in early 2004, 17 of the 36 observatories measured the heaviest snow depths in their recorded histories (which varied from 20 to 110 years depending on the observatory). Subsequently, deer populations seemed to decrease in 2004 (Fig. 8). However, the Hokkaido Prefectural authorities concluded that the data taken in 2004 must be underestimates (information from Hokkaido Prefecture). Anyway, in 2005, the population recovered to or maintained their size at 2003 levels. It has been pointed out that expanding conifer plantations offer refuge to animals from snowfall (Kaji 1995). Therefore, the habitat structure might be a very important factor for deer populations, even in relation to the effects of snow. In the winter of 2005/2006, various places in Japan had their greatest ever recorded snowfalls (data from the Japan Meteorological Agency). Forthcoming data may confirm the impact of snow on wildlife populations.

The recent decreased levels of snowfall cannot explain the decline in the serow population. They tend to inhabit snow-filled areas and should be influenced by snow to a much greater extent 
than deer. In addition, heavy snows cannot be expected in warmer areas, including the middle to low altitudes of Yakushima. The number of days with snowfall per year in lowland Yakushima did not change much from 1939 to 2005 (0.36 day/year: 1939-1949; 0.70 day/year: 1950-1959; 2.33 day/year: 1960-1969; 0.56 day/year: 1970-1979; 0.60 day/year: 1980-1989; 0.20 day/year: 1990-1999; 1.00 day/year: 2000-2005), and the maximum snow depth was $2 \mathrm{~cm}$ (data from the Japan Meteorological Agency). The trend for the snowfall in the middle altitudes is likely to be similar.

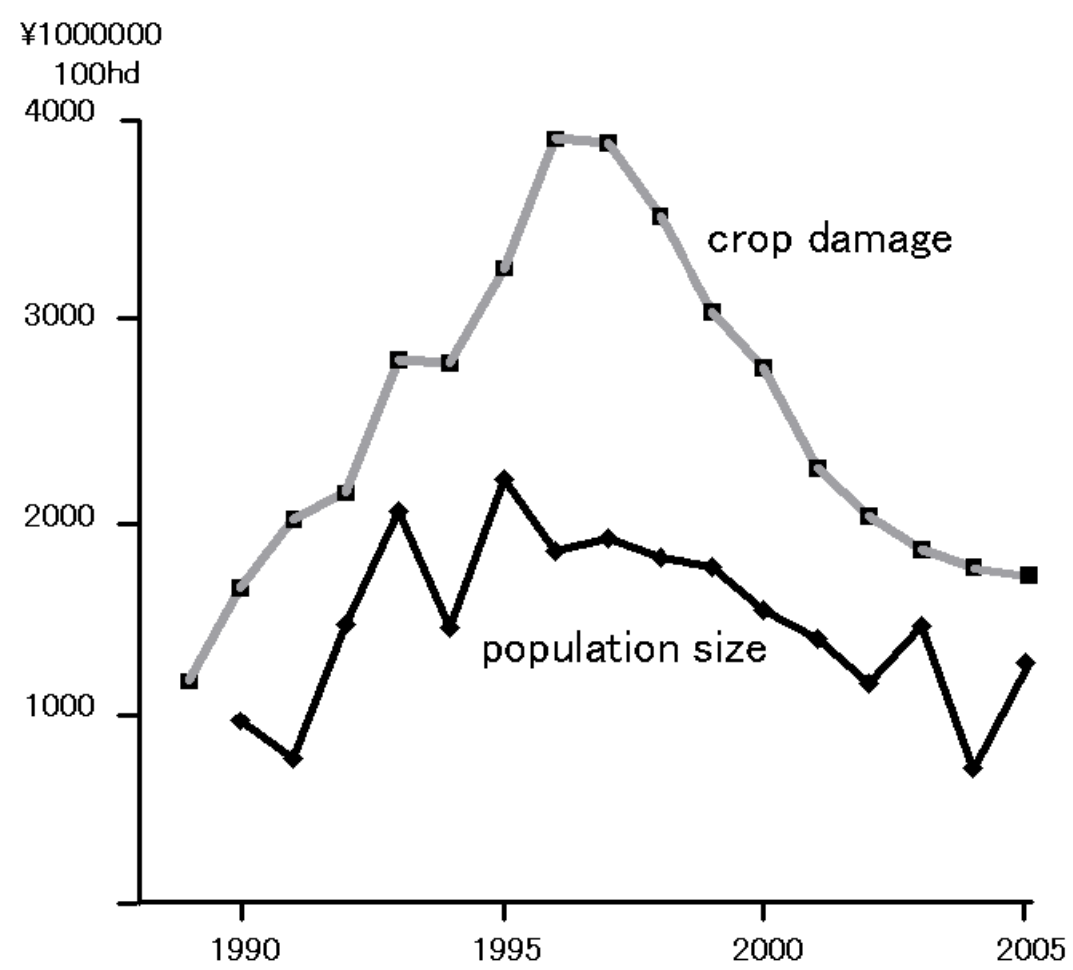

Fig. 8 Deer population and agricultural crop damage in the east part of Hokkaido Island, Japan. The solid line indicates the estimated deer population and the gray line indicates the amount of crop damage. The population size in 1994 was estimated at 200,000 by the Hokkaido Prefecture (2002). The populations in other years were calculated by averaging four relative density indices presented by the Hokkaido Pref.; sightings per unit effort from hunters (SPUE), density estimates from aerial surveys in main wintering places (three places for 1993 and 1996-2001, one place for 2002-2004), detection rates per $10 \mathrm{~km}$ of census routes, and those in main wintering places. Missing data were ignored. Since 1995, deer fences for protecting crops have been gradually elongating (over 3,000 km by 2003: Agriculture, Forestry and Fisheries Research Council et al. 2003; data from Hokkaido Pref.)

\section{- Expansion of grasslands}

The expansion of the artificial grasslands has been inferred to cause population eruption. Grasslands were often established after large-scale logging. Such grasslands produce more food for herbivores than do natural forests: they might therefore engender population eruption. However, the production is higher for 10-15 years at most; production then decreases rapidly to lower levels than 
those of natural forests for a much longer period (Fig. 1). Food conditions worsen thereafter, and population size may be limited by this lower production.

Forest roads were constructed during forest development. Some grassland strips occur at the roadsides. However, at the same time, plants cannot grow on the road surface itself or on concreted slopes around the road. Therefore, road construction has both positive and negative effects in terms of food production. Because roadside vegetation will also show successional change, the positive effects will decrease with time since construction. The forest roads also may not then have a great effect on the deer population, although they may exert some influence on the habitat use of individual animals.

The development of pastures yields much food for herbivores. However, for most parts of Japan, excluding Hokkaido Island, pasture areas are trivial (7\% for Hokkaido, but $0.7 \%$ for other parts of Japan: data from The Ministry of Agriculture, Forestry and Fisheries) in comparison to the area of forested lands (71\% for Hokkaido and 66\% for other parts: data from the Forestry Agency). Also, in Yakushima, the area of pasture is less than 0.1\% (Kagoshima Prefecture 2005), and that of the forest is $91 \%$ of the total area of the island (Kagoshima Prefecture 1992). For this reason, this factor may only be applicable to some limited areas that have many pastures. Even in such areas, habitat deterioration by logging and conifer plantations must be considered when gauging food conditions.

Some grasslands have been created unintentionally around farms. Such grasslands might attract wildlife and induce crop raiding. However, this influences habitat structures and range usage of animals rather than population eruption, even though increased population densities might occur in limited areas.

\section{- Decrease in the number of hunters}

The number of registered hunters has decreased (Internal Affairs and Communications Agency 1992) concomitant with changes in social fashions in Japan. This is presumed to be a factor that explains the burgeoning populations of deer and monkeys (e.g., Tsuji 1999; Hakusan Nature Conservation Center 1995). About 30 professional hunters lived in Yakushima around 1950 (Kamiyaku Town 1984), but few professional hunters reside there now. Members of hunter associations in Yakushima have also decreased (data from the Kagoshima Prefecture). However, we should note that hunting pressure cannot be assessed simply by the number of hunters. Hunting equipment and transportation (e.g., guns, transceivers, forest roads, automobiles, etc.) have improved considerably over the last 50 years. On the other hand, hunting skills and experience have likely declined, and hunting regulations have also undergone changes. Past hunting pressures on wildlife populations have not been adequately evaluated in Japan. Data reflecting the number of hunted animals exist in many areas in Japan, as shown in Yakushima (Fig. 3c,d). However, the task of interpreting these data is a complex one. Large numbers of hunted animals do not always imply strong hunting pressure on wildlife populations, because far more animals may remain alive, and vice versa. Notwithstanding, if the numbers of animals hunted were large over a long period, large animal populations would have to have been present to permit the steady supply of so many 
animals.

Deer hunting was strictly limited in Yakushima in the eighteenth century. Deer were controlled goods within the Shimazu Domain. People could not hunt deer freely (Kamiyaku Town 1984). In a particular village, deer hunts were conducted only three times each winter season. As a result, even in recent times, people eat venison only a few times per year (e.g., Kamiyaku Town 1984). Therefore, no proof exists that hunting pressure on deer or monkeys has ever regulated their populations in Yakushima. However, past hunting pressure should be examined more carefully by gathering as much local information as possible.

\section{The need to seek other factors}

Many Japanese researchers and administrators have inferred that the main cause of crop raiding is an "unnatural increase" in pest species because of the factors described above. Consequently, they may affirm that humans must control their numbers to "natural" or "adequate" levels to protect crops or even to conserve natural ecosystems. However, pest control measures have proved incapable of decreasing crop damage from various species of wildlife in various places. Direct control of wildlife has not mitigated their crop damage, implying that the factors that cause the problem have little to do with the mere number of animals involved. Nevertheless, so much emphasis has been placed on the mammal population eruptions that other factors and measures have not been seriously examined. It is therefore worth examining other factors and mechanisms of crop raiding from completely different points of view.

The putative factors mentioned above, excluding decreased hunters, could be adapted for limited areas or for limited wildlife species in Japan. However, agricultural crop raiding by various species increased across subtropical regions and cool temperate regions in Japan during the 1980s and 1990s (e.g., Agetsuma, 1999a). For this reason, it is reasonable to seek factors that are generally applicable to crop raiding that can be adapted to various areas and to various species.

\section{Relation between crop raiding and habitat transformations}

Large-scale loggings of natural forest and transformations to monotonous conifer plantations occurred at similar times all over Japan (Japan Federation of Bar Associations 1991). Furthermore, the reconstruction of the structure of the landscape in forests and farm areas would have changed resource allocations for wildlife during the period when the Japanese industrial structure was changed. Such land use changes produce long perturbations that trigger changes in wildlife ecology. Therefore, this factor is applicable to all of Japan and to myriad pest species. In fact, a positive relation exists between the areal occupancy of conifer plantations and crop damage by deer in the Hyogo Prefecture (Sakata et al. 2001). In addition, crop damage by monkeys was high in places with 40-50\% areal occupancy by conifer plantations (Japan Society for Preservation of Birds 1988). These imply negative influences of plantations on crop raiding.

In Yakushima, crop raiding increased rapidly for several years after 1980 for monkeys, and 
around 1990 for deer (Fig. 3c,d). However, because of the deterioration of food conditions after logging and conifer planting during those periods, their populations might have been lower than before intensive logging began. Therefore, wildlife population eruptions cannot explain the onset of intensive crop raiding. Some ecological and behavioral changes of animals are likely to cause crop raiding. If this was not the case, more crop raiding should have occurred previously (i.e., in the 1950s), when more animals inhabited the area and when much larger farm areas existed, than in the 1980s (Fig. 5). Moreover, it is impossible to explain the increased rates of crop damage at the beginning (mean 65\% per year from 1976-1981 for monkeys, and mean 46\% per year from 1990 to 1993 for deer; Fig. 3c,d) merely by population increases in pest species. Population growth rates of intensively provisioned monkeys are 10-14\% (Oita City 1977). Those of deer without predation and hunting are reported to be $15-20 \%$ at most (e.g., Hokkaido Prefecture 2002), although a 36\% increase was observed in one year after a population crash on Kinkazan Island (The Nature Conservation Society of Japan 1991).

Sometimes unclear or even reverse relationships between herbivore population densities and damage to crops, forestry and natural vegetation have been reported in Japan (e.g., Oi and Suzuki 2001; Ochiai 1996; Sakata et al. 2001), although the damage is commonly presumed to correlate with population densities (e.g., Suda and Koganezawa 2002; Hokkaido Prefecture 2002). In Yakushima, damage rates among wild plant species and plant individuals relative to deer density were much higher in plantation areas than in natural forests (e.g., Mupemo et al. 1999; Agetsuma et al. 2004). In east Hokkaido, damage caused to agricultural crops by deer increased rapidly during 1993-1998, even though the deer population was relatively constant (Fig. 8). Sakata et al. (2001) pointed out that some places with lower deer density receive greater crop damage and vice versa. Ochiai (1996) also suggested that damage of plantation trees by serow begins before their density increases. These empirical data and various other instances suggest that some functional responses (shifts in ecological strategies) play important roles in impacts on crops and vegetation, rather than simply the density of wildlife. We must note the importance of such functional responses and the ecological plasticity of wildlife if we are to understand and control their impacts. Attention must also be paid to the historical contexts of habitats and wildlife populations, not merely their current conditions (Gill et al. 1996).

The reasons why animals change ecological strategies and how they do so have never been seriously studied, but they can be explained as adaptations to fluctuations in habitat to some extent. Different ecological strategies have been understood as adaptations to habitat stability and unpredictability (e.g., Begon et al. 1986). Such adaptations explain interspecific differences in ecology. Similarly, the same species, and even the same individuals, within their respective ranges of capability, must change their ecologies in response to changes in habitat stability. Mammals have broad plasticity based on large behavioral repertoires with high abilities to learn and to physiologically adapt. These characteristics can allow them to shift their ecological strategies quickly upon great perturbations in habitat. In a fluctuating environment, generalist characteristics will be more adaptable than specialist characteristics. Therefore, mammals will tend to widen acceptable food species and ranges, and disperse to new areas in order to adapt to an unpredictable 
environment. As a result, they will tend to visit farmlands (novel places) and start to feed upon crops (novel foods). In addition, animals in less predictable environments will try to maximize their fitness within a short time frame because of the uncertainty over future benefits (e.g., Timberlake et al. 1987). Furthermore, optimum foraging theory (e.g., Charnov 1976) and experimental studies (e.g., Kacelink and Cuthill 1987; Agetsuma 1999c) show that animals facing lower food availability or dispersed food resources tend to feed longer at one food resource. These features engender intensive consumption of certain resources or resources in certain places, thereby causing intensive damage to crops and vegetation. These shifts in ecological strategies may be induced by large-scale transformations in habitat structure, which result in large perturbations.

Pest control must be an additional disturbance for wildlife populations. However, they seemed to have adapted to constant control pressures over the last 20-30 years in Yakushima because they have been able to continue damaging agricultural crops even under these pest control pressures (Fig. 3c,d). They may have retained their population size because similar control efforts since the 1980s have presumably resulted in a constant number of monkeys being controlled each year (Fig. 3c). If the size of the population of raiding monkeys has been constant (at 1,600-3,100 hd; Yoshihiro et al. 1998) since 1984, the population growth rate to compensate for the controlled animals (300-600 per year) would need to be very high compared to the intensively provisioned population growth rate (10-14\% per year; Oita City 1977), even though that population size might be underestimated. Muroyama (2003) reported that monkeys that depend on agricultural crops year-round have birth rates as high as those of intensively provisioned monkeys. However, most raiding monkeys in Yakushima seem to feed on crops (oranges) for limited seasons.

Changes in landscape structure in forests and farm areas would facilitate crop raiding. In Yakushima's middle altitudes, highly productive broad-leaved forests have been transformed into low-productivity conifer plantations (Fig. 3b). On the other hand, at lower altitudes, low-productivity treeless lands have reverted to broad-leaved forest or have been transformed into farmland (Sprague, unpublished data). The altitudes associated with the production of resources for wildlife has changed inversely from middle-to-low altitudes to low-to-middle altitudes. Similar landscape changes are also apparent in other parts of Japan that are suffering from crop raiding (Agetsuma 2006). These changes in landscape structure encourage crop raiding and make it difficult to defend crops. Morino and Koike (2006) analyzed proximate environmental factors around orange orchards that influence crop raiding by monkeys in Yakushima. They showed that intensity of crop raiding was negatively correlated with the distance from large forest patches, and positively correlated with distance from wide roads. Therefore, appropriate landscape management could decrease crop raiding by wildlife, although it may not always promote ecological function around farmlands (Agetsuma 2006).

Habitat disturbances and changes in landscape structure that induce functional responses of wildlife will be important contributing factors to crop raiding. Even if population eruptions occur in some cases, distinguishing simple population recoveries from unnatural population eruptions must be very difficult; we note that it is accompanied by a shift in ecological strategies to large environmental perturbations. Takatsuki (1996) pointed out that pest control is only a tentative 
measure for crop raiding and that habitat rehabilitation is strongly required as an essential measure.

To confirm such shifts in ecological strategies and functional responses of mammals to habitat disturbances, we must analyze more histories of the disturbances wildlife have sustained in relation to their impacts on crops, forestry and vegetation. There must be many sources of empirical data throughout Japan, although they may not be perfect, because intensive forest development and crop raiding have occurred in many places. Moreover, research into the responses of individual animals to disturbances will provide much information on the shifts in their strategies.

\section{Rehabilitation of ecological functions through land use management}

Natural forests provide more stable environments with temporally and spatially diversified resources for various wildlife species than do artificially developed areas. These ecological functions help maintain the original ecologies of wildlife. Without them, wildlife will change diet selection, range use, dispersion, demography, etc., to have "pioneering" ecologies in order to adapt to large perturbations. This shift in ecological strategies may result in functional responses to disturbances. Species that cannot shift their strategies will falter numerically or become extinct. In fact, the strongest thread linking endangered species is habitat transformation (Hilton-Taylor 2000). In this sense, crop raiding and biodiversity loss express different aspects of the same ecological function losses. Therefore, habitat management (i.e., the rehabilitation of ecological functions and the reorganization of landscape structures) should have positive effects on both problems (Agetsuma 1995c, 1998, 2006). Nevertheless, few studies have been conducted from this point of view. The specific functions and processes needed to conserve wildlife ecology in forest ecosystems must be determined for taking actual measures against crop raiding.

Destruction of natural vegetation by deer has been reported in several parts of Japan, including Yakushima, as being a serious environmental problem (Yumoto and Matsuda 2006). To resolve this problem, we should note first that most natural vegetation has already been disturbed by forest transformation. Large-scale forest transformation deprives the original habitat of various plant species as a direct effect. These transformations may encourage deer to damage vegetation as a side effect. Therefore, habitat rehabilitation is required in order to conserve vegetation and natural ecosystems.

Presuming that there is an "ideal" or "expected" relationship among wildlife, vegetation and humans to conserve an ecosystem, we must devote careful attention to the relationships between them before performing heavy logging and planting. Most of our scientific knowledge of the dynamics of wildlife and forests has been obtained since the large transformations of the forests. Meanwhile, wildlife and plants have endured continual disturbances and have adapted to them. In more stable environments, or their original environments, they might show different dynamics and relationships. Attempts to conserve ecosystems and maintain ecological functions and services should make use of the many clues provided by the relationships among wildlife, natural vegetation and human activity that occurred before the great forest transformations (Agetsuma 2005).

This study specifically addressed natural processes of agricultural crop raiding by wildlife 
in Japan. However, adaptations of society to this problem (through sociological, economic and political processes) also play an important role when elucidating the problem and prescribing its solution (Agetsuma 1999b).

\section{Acknowledgments}

I thank Prof. Nakashizuka of Tohoku University for encouraging me to write this paper, the Forest and Fisheries Department of Kagoshima Pref. for providing me with local data, Mr. Suwa for providing data on forestry in Yakushima, Dr. Hill of the University of Sussex for improving the manuscript, and the PRI of Kyoto University for allowing me to use Yakushima Field Research Station. This study was supported by a grant from the Fujiwara Natural History Foundation, Grants-in Aid for Young Scientists (A) 14704013 and (B) 16780107 from The Ministry of Education, Culture, Sports, Science and Technology of Japan, and Research Projects of the RIHN.

\section{References}

Agetsuma N (1995a) Foraging strategies of Yakushima macaques (Macaca fuscata yakui). Int J Primatol 16:595-609.

Agetsuma N (1995b) Dietary selection by Yakushima macaques (Macaca fuscata yakui): the influence of food availability and temperature. Int J Primatol 16:611-627.

Agetsuma N (1995c) Methods of vegetation rehabilitation for wildlife conservation (in Japanese with English summary). Primate Res 11:133-146.

Agetsuma N (1996) Nature conservation and wildlife in the island of Yakushima (in Japanese). Wildl Forum 2:23-32.

Agetsuma N (1998) Crop damage by wild Japanese monkeys on Yakushima Island, Japan (in Japanese with English abstract). Jpn J Conserv Ecol 3:43-55.

Agetsuma N (1999a) Present situation of Japanese wildlife reviewed from economic backgrounds:

An introduction for young students. J Econ Dept Akita Univ Econ Law 30:11-23.

Agetsuma N (1999b) Roles of primatology for wildlife management (in Japanese). In: Nishida T,

Uehara S (eds) An introduction to field primatology. Sekaishisosha, Tokyo, pp 300-326.

Agetsuma N (1999c) Simulation of patch use by monkeys in operant schedule. J Ethol 16:49-55.

Agetsuma N (2001) Relation between age-sex classes and dietary selection of wild Japanese monkeys. Ecol Res 16:759-763.

Agetsuma N (2005) Food web (in Japanese). In: Nakamura F, Koike T (eds) Forest sciences. Asakura, Tokyo, pp 80-83.

Agetsuma N (2006) Conservation of wildlife (in Japanese). In: Field Science Center for Northern Biosphere, Hokkaido University (ed) Introduction to field sciences. Sankyo, Tokyo, pp 98-108. Agetsuma N, Agetsuma-Yanagihara Y (2006) Ecology of Yaku sika deer in the island of Yakushima (in Japanese). In: Ohsawa M, Tagawa H, Yamagiwa J (eds) World heritage, Yakushima. Asakura, Tokyo, pp 143-149. 
Agetsuma N, Noma N (1995) Rapid shifting of foraging pattern by Yakushima macaques (Macaca fuscata yakui) as a reaction to heavy fruiting of Myrica rubra. Int J Primatol 16:247-260.

Agetsuma N, Sugiura H, Hill DA, Agetsuma-Yanagihara Y, Tanaka T (2003) Population density and group composition of Japanese sika deer (Cervus nippon yakushimae) in ever-green broad leaved forest of Yakushima, southern Japan. Ecol Res 18:475-483.

Agetsuma N, Tsujino R, Kimura A, Kurotaki T, Baba K, Fukamachi N (2004) Evaluation of a forest as deer habitat (in Japanese). In: Sugiura H, Kaneko Y (eds) The 5th Yakushima field work course. Kamiyaku Town and Kyoto University, Inuyama, pp 14-18.

Agriculture, Forestry and Fisheries Research Council, Forest and Forest Product Research Institute, National Agriculture and Bio-oriented Research Organization (2003) Basic knowledge for protecting products of agriculture and forestry from wildlife damages (in Japanese). Agriculture, Forestry and Fisheries Research Council, Tokyo.

Asahi M, Izumi T, Nagai M, Hirabayashi T, Numaguchi K, Otsuka J (1984) Sika deer (Cervus nippon yakushimae) in the Yaku-shima Wilderness Area and its adjacent region, Yaku-shima Island, Kyushu, Japan (in Japanese with English summary). In: Environment Agency (ed) Nature of Yakushima. The Nature Conservation Society of Japan, Tokyo, pp 503-516.

Azuma S (1984) Monkeys, forests and people (in Japanese). Monkey 28:94-102.

Begon M, Harper JL, Townsend CR (1986) Ecology: individuals, populations and communities, 3rd edn. Blackwell Science, Oxford.

Boyce MS (1998) Ecological-process management and ungulates: Yellowstone's conservation paradigm. Wildl Soc Bull 26:391-398.

Charnov EL (1976) Optimal foraging, the marginal value theorem. Theor Pop Biol 9:129-136.

Dussault C, Ouellet J, Courtois R, Huot J, Breton L, Jolicoeur H (2005) Linking moose habitat selection to limiting factors. Ecography 28:619-628.

Environment Agency (1984) Nature of Yakushima (in Japanese). The Nature Conservation Society of Japan, Tokyo.

Fujimura S (1971) Forest development and nature conservation (in Japanese). Water-Utility Research Institute Japan, Tokyo.

Furuichi T, Takasaki H, Sprague DS (1982) Winter range utilization of a Japanese macaque troop in a snowy habitat. Folia Primatol 37:77-94.

Gill RMA, Johnson AL, Francis A, Hiscocks K, Peace AJ (1996) Changes in roe deer (Capreolus capreolus L.) population density in response to forest habitat succession. For Ecol Manage 88:31-41.

Hakusan Nature Conservation Center (1995) Researches on management of wildlife population and techniques to control their damages in agriculture, forestry and fisheries (in Japanese). Hakusan Nature Conservation Center, Yoshinodani.

Hanya G (2004) Diet of a Japanese macaque troop in the coniferous forest of Yakushima. Int J Primatol 25:55-71.

Hanya G, Yoshihiro S, Zamma K, Matsubara H, Ohtake M, Kubo R, Noma N, Agetsuma N, Takahata Y (2004) Environmental determinants of the altitudinal variations in relative group 
densities of Japanese macaques on Yakushima. Ecol Res 19:485-493.

Hanya G, Zamma K, Hayaishi S, Yoshihiro S, Tsuriya Y, Sugaya S, Kanaoka MM, Hayakawa S, Takahata Y (2005) Comparisons of food availability and group density of Japanese macaques in primary, naturally regenerated, and plantation forests. Am J Primatol 66:245-262.

Hartemink AE (2005) Plantation agriculture in the tropics. Environmental issues. Outlook Agr 34:11-21.

Hill DA, Agetsuma N, Suzuki S (1994) Preliminary survey of group density of Macaca fuscata yakui in relation to logging history at seven sites in Yakushima Japan. Primate Res 10:85-93.

Hilton-Taylor C (2000) 2000 IUCN Red List of threatened species. International Union for the Conservation of Nature, Gland, Switzerland.

Hirose S (1984) Hunters of Yakushima (in Japanese). Monkey 28:82-87.

Hokkaido Prefecture (2002) Management plan of Ezo sika deer (in Japanese). Hokkaido Prefecture, Sapporo.

Inagaki H (1999) An occurrence of trees fallen by storm due to the difference of the vegetation and the following slope failures (in Japanese with English abstract). J Jpn Soc Eng Geol 40:196-206.

Inoue S, Sakaguchi M, Mori H, Miyamura K, Ujiie A, Shigehara S, Noguchi Y (1986)

Seroepidemiology of Sugi (Japanese cedar) pollinosis. Increase of $\operatorname{IgE}$ antibody positive rate in recent years (in Japanese). Igaku No Ayumi 138:285-286.

Internal Affairs and Communications Agency (1992) Survey on status of wildlife conservation (in Japanese). Internal Affairs and Communications Agency, Tokyo.

Itani J (1994) Nature and people in Yakushima (in Japanese). Seimei No Shima 30:25-29.

Izawa K, Kasuya T, Kawamichi T (1996) The encyclopaedia of animals in Japan, vol. 2: Mammal II (in Japanese). Heibonsha, Tokyo.

Japan Federation of Bar Associations (1991) Consideration of future forests (in Japanese). Yuhikaku, Tokyo.

Japan Institute of Land and Environmental Studies (1981) Research on mudslides occurred in

Kamiyaku Town, Kagoshima Prefecture (in Japanese). Kokudo Mondai 22:1-86.

Japan Society for Preservation of Birds (1988) Survey on measures to control damages by wildlife:

Japanese monkey and common cormorant (in Japanese). Environment Agency, Tokyo.

Kacelink A, Cuthill IC (1987) Starlings and optimal foraging theory: modelling in a fractal world.

In: Kamil AC, Krebs JR, Pulliam HR (eds) Foraging behavior. Plenum, New York, pp 303-333.

Kagoshima Dairinkusho (1916) Statistics of Kagoshima Dairinkusho (in Japanese). Kagoshima

Dairinkusho, Kagoshima.

Kagoshimaken Shizen Aigo Kyokai (1981) Survey of distribution of Yaku sika deer (in Japanese).

Kagoshimaken Shizen Aigo Kyokai Chousahoukoku 5:1-34.

Kagoshima Prefecture (1992) Master plan of the Yakushima Environmental Culture Village (in Japanese). Kagoshima Prefecture, Kagoshima.

Kagoshima Prefecture (2005) Annual statistics of Kagoshima Prefecture (in Japanese). Kagoshima Prefecture, Kagoshima.

Kaji K (1995) Deer irruptions_-a case study in Hokkaido, Japan (in Japanese). Mamm Sci 


\section{$35: 35-43$.}

Kamiyaku Town (1984) Chronicle of Kamiyaku Town (in Japanese). Kamiyaku Town, Kamiyaku.

Kay CE (1998) Are ecosystems structured from the top-down or bottom-up: a new look at an old debate. Wildl Soc Bull 26: 484-498.

Koganezawa M (1999) Changes in the population dynamics of Japanese serow and sika deer as a results of competitive interactions in the Ashio Mountains, central Japan. Biosphere Conserv 2:35-44.

Koizumi T. (1988) Management of sika deer in Hokkaido. The effects of forest management and hunting on the deer populations (in Japanese with English summary). Res Bull Hokkaido Univ Forests 45:127-186.

Lugo AE (1997) The apparent paradox of reestablishing species richness on degraded lands with tree monocultures. For Ecol Manage 99:9-19.

Maeto K, Sato S, Miyata H (2002) Species diversity of longicorn beetles in humid warm-temperate forests: the impact of forest management practices on old-growth forest species in southwestern Japan. Biodiversity Conserv 11:1919-1937.

Matsuda T (1997) Wonder stories on Yakushima (in Japanese). Shusakusha, Tokyo.

Matsuda H, Kaji K, Uno H, Hirakawa H, Saitoh T (1999) A management policy for sika deer based on sex-specific hunting. Res Popul Ecol 41:139-149.

McNeely JA, Miller KR, Reid WV, Mittermeier RA, Werner TB (1990) Conserving the world's biological diversity. IUCN, Gland; WRI, Baltimore; World Bank, Philadelphia.

Messier F (1991) The significance of limiting and regulating factors on the demography of moose and white-tailed deer. J Anim Ecol 60:377-393.

Ministry of the Environment (2000) Management manual for designated wildlife species (in Japanese). Ministry of the Environment, Tokyo.

Miura K (1984) Nature conservation of Yakushima (in Japanese). Monkey 28:64-69.

Miura S (1999) Wildlife ecology and damages on agriculture and forestry (in Japanese). National Forestry Extension Association in Japan, Tokyo.

Miyamoto T (1974) Folklore of Yakushima (in Japanese). Mirai-sha, Tokyo.

Miyawaki A, Okuda S (1978) Handbook of Japanese vegetation (in Japanese). Shibundo, Tokyo.

Morino M, Koike F (2006) Assessing the risk of economic damage to crops caused by Japanese macaques on Yakushima Island (in Japanese with English abstract). Jpn J Conserv Ecol 11:43-52.

Mupemo FC, Anantasran J, Harunari M, Hsu S, Kubo S, Ali W, Agetsuma N (1999) Population census of Yakushima deer. In: Yumoto T, Matsubara T (eds) Yakushima international field biology course. DIWPA, Kamiyaku Town, CER of Kyoto University, JCISE, Kyoto, pp $155-192$.

Muroyama Y (2003) To get along with monkeys around the village (in Japanese). Kyoto University Press, Kyoto.

Nagaike T (2002) Differences in plant species diversity between conifer (Larix kaempferi) plantation and broad-leaved (Quercus crispula) secondary forests in central Japan. For Ecol 
Manage 168:111-123.

Nagata S, Inoue M, Oka H (1994) Forest utilization pattern in the course of economic development. In an inquiry of the U-shaped hypothesis of forest resources (in Japanese with English summary). Rural Culture Association, Tokyo.

Nakane K (1995) Soil carbon cycling in a Japanese cedar (Cryptomeria japonica) plantation. For Ecol Manage 72:185-197.

Nawa A, Takayanagi A (2001) Population changes of Japanese serow and sika deer exposed by a point observation at southern part of the Suzuka Mountains, central Japan (in Japanese). Spec Publ Nagoya Soc Mammalog 3:58-63.

Ochiai K (1996) Effects of forest management on Japanese serow populations in relation to habitat conservation for serows (in Japanese). Mamm Sci 36:79-87.

Ohsawa H, Yamagiwa J, Hill DA, Agetsuma N, Suzuki S, Vadher SKA, Biggs AJ, Matsushima K, Kubo R (1995) Disturbances of ecology of wildlife by cedar plantation in Yakushima Island, WWF-J Report (in Japanese). Yakushima Wildlife Conservation Project, Inuyama.

Oi T, Suzuki M (2001) Damage to sugi (Cryptomeria japonica) plantations by sika deer (Cervus nippon) in northern Honshu, Japan. Mamm Study 26:9-15

Oita City (1977) Survey on Japanese monkeys in Takasakiyama 1971-1976 (in Japanese). Oita City, Oita.

Peterson RO (1999) Wolf-moose interaction on Isle Royale: the end of natural regulation? Ecol Appl 9:10-16.

Ripple WJ, Beschta RL (2004) Wolves, elk, willows, and trophic cascades in the upper Gallatin Range of Southwestern Montana, USA. For Ecol Manage 200:161-181.

Saitoh T, Nakatsu A (1997) The impact of forestry on the small rodent community of Hokkaido, Japan. Mamm Study 22:27-38.

Sakata H, Hamasaki S, Kishimoto M, Mitsuhashi H, Mitsuhashi A, Yokoyama M, Mitani M (2001) The relationships between Sika deer density, hunting pressure and damage to agriculture in Hyogo Prefecture (in Japanese with English abstract). Hum Nat 12:63-72.

Sanchez E, Gallardo C, Gaertner MA, Arribas A, Castro M (2004) Future climate extreme events in the Mediterranean simulated by a regional climate model: a first approach. Global Planet Change 44:163-180.

Shirai K (1993) Home range and habitat use of Japanese monkeys in the plantation area in Okutama, Tokyo (in Japanese). Primate Res 9:300.

Singer FJ, Swift DM, Coughenour MB, Varley JD (1998) Thunder on the Yellowstone revisited: an assessment of management of native ungulates by natural regulation, 1968-1993. Wildl Soc Bull 26:375-390.

Skogland T (1991) What are the effects of predators on large ungulate populations? Oikos 61:401-411.

Sone K, Okumura H, Abe M, Kitahara E (1999) Biomass of food plants and density of Japanese serow, Capricornis crispus. Mem Fac Agr Kagoshima Univ 35:7-16.

Stockton SA, Allombert S, Gaston AJ, Martin J (2005) A natural experiment on the effects of high 
deer densities on the native flora of coastal temperate rain forests. Biol Conserv 126:118-128.

Sueyoshi M (1992) Damages by sika deer on Yakushima, Kagoshima Prefecture (in Japanese). For Pests 41:33-35.

Suda K, Koganezawa M (2002) Natural population density of sika deer considering forest ecosystem biodiversity (in Japanese with English abstract). Environ Res Quart 126:43-49.

Tagawa H (1987) Researches on dynamics and management of biosphere reserves (in Japanese). In: Research on dynamics and management of Yakushima Biosphere Reserve. Research Team of "Dynamics and Management of Yakushima Biosphere Reserve", Kagoshima, pp 1-11.

Tagawa H (1994) Natural World Heritage, Yakushima (in Japanese). Japan Broadcast Publishing, Tokyo.

Takatsuki S (1990) Summer dietary composition of sika deer on Yakushima Island, southern Japan. Ecol Res 5:253-260.

Takatsuki S (1992) Sika deer living in the North (in Japanese). Dobutsusha, Tokyo.

Takatsuki S (1996) Conservation of common species (in Japanese). In: Higuchi H (ed) Conservation biology. University of Tokyo Press, Tokyo, pp 191-220.

The Nature Conservation Society of Japan (1991) Wildlife conservation (in Japanese). The Nature Conservation Society of Japan, Tokyo.

Timberlake W, Gawley DJ, Lucas GA (1987) Time horizons in rats foraging for food in temporally separated patches. J Exp Psychol 13:302-309.

Tsuji M (1999) Can we protect forests of Nikko from deer damages? (in Japanese). Zuisousha, Utsunomiya.

Wildlife Workshop (2003) Annual report of Serow population survey in Yamagata City (in Japanese). Wildlife Workshop, Yamagata.

Yumoto Y, Matsuda H (2006) Deer eat World Heritage (in Japanese). Bun-ichi Sogo Shuppan, Tokyo.

Yamabayashi N (1962) Forestry (in Japanese). Morikita, Tokyo.

Yoshihiro S, Fruichi T, Manda M, Ohkubo N, Kinoshita M, Agetsuma N, Azuma S, Matsubara H, Sugiura H, Hill D, Kido E, Kubo R, Matsushima K, Nakajima K, Maruhashi T, Oi T, Sprague D, Tanaka T, Tsukahara T, Takahata Y (1998) The distribution of wild Yakushima macaque (Macaca fuscata yakui) troops around the coast of Yakushima Island, Japan. Primate Res 14:179-187. 